\title{
Research on the Reform of Postgraduate Education and Teaching in Response to the Social Demands in the New Era
}

\author{
Shuo Yang, ${ }^{1, *}$ Qiaosheng Deng ${ }^{1}$, Qiaonan Zhao ${ }^{1}$, Honggang Pan $^{1}$, Yu Gao ${ }^{1}$, \\ Shanshan $\mathrm{Ma}^{1}$, Jie Cui ${ }^{1}$, Yudong Fu${ }^{1}$, Guofeng Wang ${ }^{1}$, Deyang Sui ${ }^{1}$, Xinle Yang ${ }^{2}$ \\ ${ }^{1}$ Key Laboratory of Liaoning Province for Clean Combustion Power Generation and Heating Technology, Shenyang \\ Institute of Engineering, Shenyang, China \\ ${ }^{2}$ School of Mechanical Engineering, Liaoning Technical University, China \\ *Corresponding author. Email: ys_yang_shuo@163.com
}

\begin{abstract}
Under the background of socialism with Chinese characteristics entering a new era, in order to meet the needs of the society and the country for high-level personnel, it is necessary to strengthen practice and theoretical application. Based on the current development of school-enterprise cooperation, analyzing the existing problems in current education and teaching of graduate students in colleges and universities, put forward suggestions for optimizing the way of project setting and strengthening the mental health counseling of students, so as to provide direction for the research on the reform of postgraduate education and teaching.
\end{abstract}

Keywords: Higher education, Postgraduate training, Engineering practice, Mental health.

\section{INTRODUCTION}

Under the background of socialism with Chinese characteristics entering a new era, a new journey towards building a modern socialist country on the basis of the successful of poverty elimination and a moderately prosperous society establishment, the development of the party and the country urgently needs to train a large number of high-level personnel with both ability and moral integrity. Postgraduate education and teaching methods need to be adjusted accordingly to meet the needs of the country and the society. Postgraduate education plays an important role in cultivating innovative talents, improving innovation capabilities, serving economic and social development, and promoting the modernization of the China's system and capacity for governance. With the continuous advance of China's innovation-driven development, the demand for engineering scientific and technological talents is becoming increasingly prominent in economic and social development. So that cultivating a group of diversified, innovative and outstanding engineering-scientific talents has become one of the main directions of the innovation in postgraduate education and teaching methods.

Engineering practice and theoretical application is one of the footholds of postgraduate education. Engineering practice plays a very important role in improving students' practical and innovation abilities ${ }^{[1]}$, which also have facilitation on theoretical knowledge acquirement and theoretical-practice combination for students. However, the traditional engineering practice content, models and methods cannot meet the needs of the society and the country for high-level engineering personnels under the background of the new economy and new era. In order to solve this problem, cultivate students with higher innovative thinking ability and theoretical application ability to play a role in the development of the industry, which has become an important subject of engineering practice teaching reform research in the process of graduate education and teaching ${ }^{[2]}$. School-enterprise cooperation is the main form and carrier of student engineering practice in the process of current graduate education and teaching. The direction of postgraduate education and teaching can be aimed at the frontiers of science and technology and key fields by the joint training of universities and enterprises. So that postgraduate education can keep up with the 
development of science and technology and the frontier of the industry, which also plays as a positive role in promoting the adjustment of disciplines and majors. In order to further promote school-enterprise cooperation, it is necessary to innovate and reform the engineering practice teaching in the process of the postgraduate education and teaching under the background of the new era. The key point of development is to combine engineering practice with theoretical application.

\section{PROBLEMS IN HIGHER EDUCATION}

In order to meet the needs of social development and national development, The purpose of education is not clear, education and teaching are not centered on student development and insufficient attention to the mental health of postgraduates problems are the primary content to realize the innovation of postgraduate education and teaching methods. Figure 1 is a block diagram of the current problems in postgraduate education.

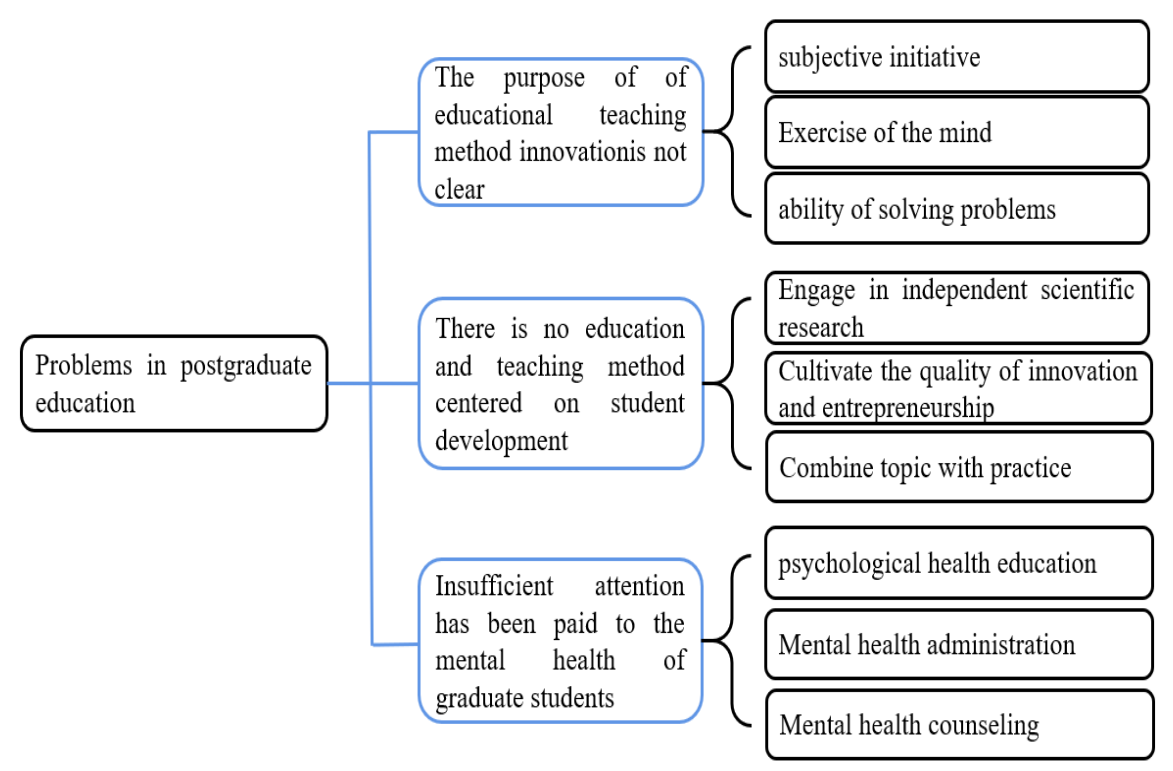

Figure 1 The current problems in postgraduate education

\subsection{The Purpose of Education is not Clear}

The purpose of postgraduate education and teaching is to optimize the strategic layout of the school's talents and comply the social and economic development ${ }^{[3]}$. To achieve this goal, integrating innovative education models into talent training is an important direction for the reform of postgraduate education and teaching. According to modern learning theory, student's learning process is a process in which they actively construct knowledge by using knowledge taught by teachers. It has the characteristics of interaction and continuous growth, and is affected by existing knowledge, learning attitude, learning motivation and learning style. Students' understanding and learning of knowledge is a process of digesting and absorbing higher experience and thinking ability based on their own existing experience and thinking ability, students must always maintain the conversion and communication between the reality they know and the knowledge they have learned. Therefore, the core of education and teaching method innovation in postgraduate education is to change the traditional teaching mode from the teacher's teaching-centered to student-centered learning, which gives a full play to the subjective initiative of students in learning. In the teaching process, attention should be paid to the cultivation of students' ability to discover and solve problems, sufficient encouragement, help and support should be provide to students' active learning, so as to promote the formation of good study habits, and then obtain the exercise of thinking and all-round development of attitude and emotion ${ }^{[4]}$.

Under the background of socialism with Chinese characteristics entering a new era, a new journey towards building a modern socialist country on the basis of the successful of poverty elimination and a moderately prosperous society establishment, the development of the party and the country urgently needs to train a large number of high-level personnel with both ability and moral integrity. In the process of postgraduate education and teaching, it is necessary to clarify the purpose of teaching methods innovation, further strengthen students' subjective initiative in learning and makes students actively thinking, which has a positive effect on the engineering practice teaching reform in the process of postgraduate education and teaching. 


\subsection{The Formation of Education and Teaching Method do not Centered on Students' Development}

The objectives of postgraduate education and teaching are as follows: all-round development of moral, intelligence and physical, and master substancial basic theories and systematic expertise in the subject, having the ability to engage in scientific research, teaching work or independently undertake specialized technical work. Graduate students under doctor degrees should have the ability to engage in scientific research independently, and are senior professionals with creative achievements in science or special technology. The decisions and plans of education and teaching in universities should be centered on students based on this training goal ${ }^{[5]}$. The development of student-centered education and teaching methods can be achieved by vigorously developing a school-enterprise cooperation model and implementing resource complementation in the combination of production, learning, and research, so as to make full use of resources and achieve win-win results. By setting up a school in factory or a factory in school, making full use of the resources provided by enterprises and schools, which can maximize the advantages of resources ${ }^{[6]}$. boldly innovate student-oriented education and teaching models, and cultivate students' innovative and entrepreneurial qualities and professional skills. Entrepreneurship education mechanism should be advocate, and entrepreneurship ability need to be cultivate under the interaction of teaching, production and market by opening interactive teaching with the society. Setting up a specialized and entrepreneurial experimental training bases which are integrated with school and enterprise by combining the professional education with entrepreneurial education.

In addition, schools should create a better learning and living conditions for students, the foundation of education and teaching's development is to provide material guarantees for student's scientific research work. Under this premise, the combination of students' research direction, research topics and practice are conductive to their understanding and application of the theoretical knowledge. From the perspective of sustainable development, it is beneficial to help students choose the direction of employment.

\subsection{Insufficient Attention to the Mental Health of Students}

With the development of the school mental health campaign carried out in recent years, the mental health problem of college students has always been concerned by psychologists, pedagogy and medical workers. Literature search shows that most of the existing researches are aimed at investigating the mental health development of undergraduate and junior students in college, and there is a lack of in-depth investigation and discussion on the mental health of postgraduate students [7]. Postgraduate students have different characteristics from undergraduates, such as a large age span, a small number of people, and heavy academic and scientific tasks, so that they may be faced with greater psychological pressure than undergraduates. As the high quality knowledge talents cultivated by our country, postgraduates have long-term mental unhealthiness that may cause great harm to individuals and society, such as elite crimes and campus suicides. Therefore, understand the mental health status of the postgraduate group, master its characteristics and rules, strengthen the mental health education, management and guidance of the postgraduate group, create a healthy and harmonious learning and living environment for postgraduates, and guide the normal psychological development of the postgraduate group is very necessary in the reform of the postgraduate education and teaching method ${ }^{[8]}$.

\section{EFFECTIVE MEANS FOR THE INNOVATION AND REALIZATION OF POSTGRADUATE EDUCATION AND TEACHING METHODS}

In order to speed up the postgraduate education and teaching reform process and improve the current postgraduate training method, it is necessary to optimize the setting of postgraduate subjects. As the suicide incidents caused by mental health problems of postgraduate students have occurred many times in recent years, so that it is very necessary to strengthen the guidance for students' mental health. Figure 2 is a block diagram of postgraduate education and teaching innovation methods proposed in response to the above problems. 


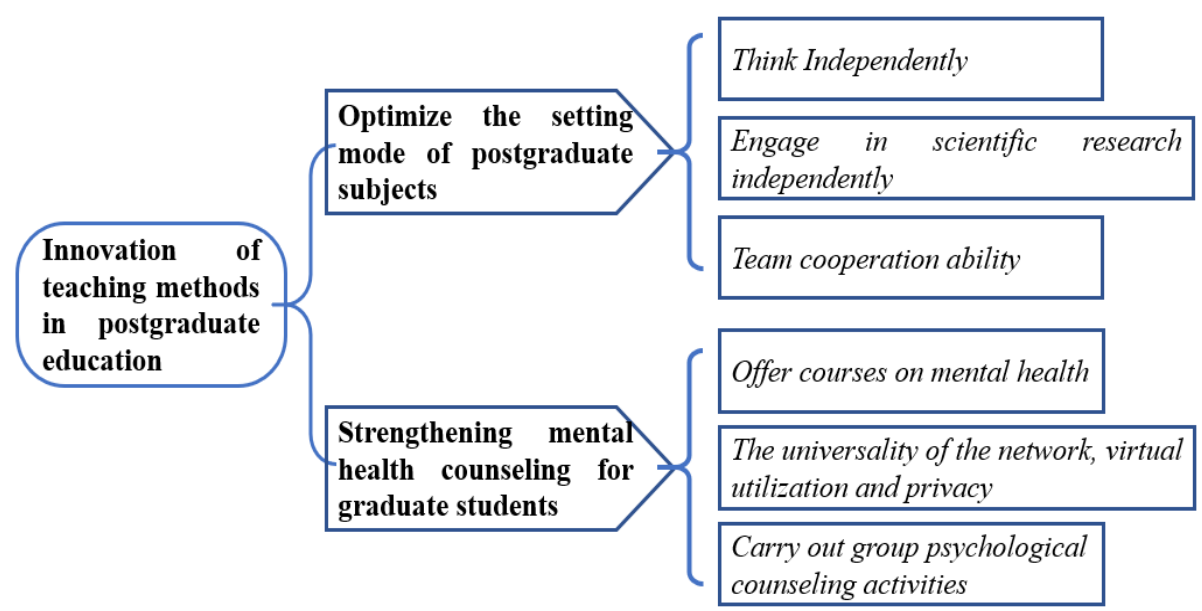

Figure 2 Innovative teaching methods for graduate education

\subsection{Optimizing the Postgraduate Students' Project Settings}

The continuous expansion of graduate enrollment has led to an imbalance in the teacher-student ratio in some colleges and universities. In order to solve this problem, tutors can distinguish each postgraduate student' research topics obviously when their topic is setting up respectively. This sort of topic setting method is beneficial to exercise the independent thinking and problem-solving ability of postgraduate students, which can also avoid the influence of the research efficiency due to the interdependence among the postgraduate students. In order to further promote the reform of postgraduate education and teaching, It is necessary to decompose the corresponding research topics into independent and interdependent sub-topics from the perspective of the large task when the postgraduate research topic is being set up. On one hand, it is necessary for postgraduate students to maintain relative independence, independent thinking and summary of phased results of research due to the different contents of the task, which are conducive to cultivate students' ability in engaging in the scientific research independently. On the other hand, since the final solution of the task is the same, although the completion methods are different, postgraduate students can use for reference in the obtained research results and shorten the research time through the research group meeting, personal communication and discussion with their tutors. It is easy to achieve mutual coordination and cooperation with other postgraduate students in this process. At the same time, in order to exercise the collaborative ability of graduate students, and provide practical opportunities for postgraduate students to integrate into the research team as soon as possible, the tutor can also guide graduate students to solve the bottleneck problem of a certain plan according to the progress of different research projects ${ }^{[9]}$.

\subsection{Strengthen the Mental Health Counseling for Postgraduate Students}

The mental health of postgraduates should be focuses on applying psychology and sociology knowledge to their mental health education, but the education work is a huge systematic project, and the implementation of postgraduate mental health education still needs continuous improvement. Some colleges and universities offer mental health courses for postgraduate students by teaching mental health knowledge and mental health knowledge. Some other colleges and universities also have carried out group psychological counseling activities, which is between individual counseling and psychological popularization education, and is an effective way to enhance postgraduate mental health education. This sort of group counseling requires trained professional psychological counselors with corresponding psychological counseling institutions to standardize the mental health counseling of graduate students. It is also an effective way to carry out mental health education through the network by utilizing the universality, virtuality and privacy of the network for postgraduate students to seek for psychological help and self-help conveniently. This form of online mental health education is in its infancy and still has much room for its development.

The emphasis in the process of postgraduate education and teaching reform should be academic psychological counseling due to the own particularities of the postgraduate students' psychological counseling, In order to avoid the mental health crisis of postgraduate students and enable them to complete their studies successfully, tutors, schools, and postgraduate students themselves need to pay attention to the pressure they were facing at, and constantly explore the ways and methods to relieve the pressure. A personal-tutor-school linkage mechanism should be established, so that each link can give full play to its role and value to relieve the psychological pressure of postgraduate students and improve their mental health level ${ }^{[10]}$. 


\section{CONCLUSION}

Under the background of the socialism with Chinese characteristics entering a new era, Postgraduate education plays an important role in cultivating innovative talents, improving innovation capabilities, serving economic and social development, and promoting the modernization of the China's system and capacity for governance.

\section{ACKNOWLEDGMENTS}

The present work has been supported by the Liaoning Province Natural Science Foundation (20180550472), the Liaoning Province Department of Education Fund (JL-2003 and JL-1914), the Shenyang young and middle-aged scientific and technological innovation team support project (RC190342), Science and Technology Foundation Project of Shenyang Institute of Engineering (2020JYYB06 and 2020JYYB22).

\section{REFERENCES}

[1] Ming Yi. "New engineering" construction action line- "Tianjin University Action". Research in Higher Education of Engineering. 2017, (2):29-30. (in China)

[2] Jiang Li, Kaijun Jin, Wenchang shi, Qiuping Yang, Jinliang An. Exploration on the reform of engineering training course teaching mode in regional universities under the new engineering background. Journal of Higher Education. 2020, (32):122-125. (in China)

[3] Jie Ma, Yongpan Wang, Yajie Niu. Research on graduate employment guidance model with innovation and entrepreneurship ability as the core. Pioneering with Science \& Technology Monthly. 2020,33(01):109-112. (in China)

[4] Wei Wang. Teaching method innovation: the important path of higher education reform. Journal of Hunan University of Science and Engineering. 2015, 36(4):162-164. (in China)

[5] Liang Na. Investigation and analysis of the status quo of national sports in colleges and universities in Ningxia. The Science Education Article Collects. 2012, (3):147-147. (in China)

[6] Qilin Zeng. Innovate education and teaching mode to improve the quality of personnel training. Liaoning Education, 2012(20):37-39. (in China)

[7] Juan Li, Hong Wang, Wei Li, Jin Li, Yang Wang. Qualitative study on prevention and control countermeasures of mental health problems of postgraduates. Chinese Health Service Management. 2010, 27(10):702-704. (in China)

[8] Yang Wang, Yong Liu. Analysis on the mental state of freshmen of graduate students in universities. Journal of Social Science of Jiamusi University. 2016,34(3):184-186. (in China)

[9] Qibing Chang, Xia Wang. Innovation and collaboration consciousness education of graduate students under the background of new engineering. Education Teaching Forum. 2019, (31):161-163. (in China)

[10] Lei Liu, Xinghua Duan. The status quo of mental stress and its influence on mental health of postgraduates. Journal of Inner Mongolia Agricultural University (Social Science Edition). 2017,19(95):112-114. (in China) 